\title{
The Relationship between Morphological Awareness and Vocabulary Knowledge of Thai EFL Students
}

\author{
Sarunya Tarat \\ Naresuan University International College, Naresuan University, Phitsanulok, Thailand
}

\begin{abstract}
This study focuses on the relationship between morphological awareness and vocabulary knowledge of English among Thai EFL university students. All participants are taking English language as their major field in the universities situated at the lower northern region of Thailand. The morphological awareness identification test was employed to identify the linkage between morphological awareness and vocabulary gain Thai EFL learners. The test was divided into 2 parts: self-checking and morpheme identification. Fifty English vocabularies in intermediate and upper-intermediate level were used in the test in which the participants were requested to check whether they have seen the vocabularies in the test and also asked to break those vocabularies into morphemic units. The results showed that the participants possessed an adequate level of morphological awareness to break words into morphemes correctly even though they were unknown words of the participants. Additionally, the findings also revealed that there is no significant difference between male and female in acquiring morphological awareness of English and gaining English vocabularies.
\end{abstract}

Index Terms—morphological awareness, vocabulary knowledge, EFL learners, university students

\section{INTRODUCTION}

As learning in the 21st century, learners are required to acquire leaning skills, literacy skills, and life skills and improve those skills to be in the digital age successfully (Thoughtful Learning, 2017). Literacy skill is the skill that learners need to have so that they are able to read and write fluently to apply, analyze, and evaluate texts in different forms (National Council of Teacher of English, 2013). Therefore, building and strengthening vocabulary knowledge is important for literacy skill development.

As mentioned, vocabulary knowledge is essential to develop learner's literacy skill; learners need to have sufficient knowledge and use their prior knowledge to identify words in reading and to take ideas and organize them in writing because reading and writing skills are the processes of constructing word meaning (Tomkins, 2013). Vocabulary knowledge links to morphological awareness because it leads to vocabulary acquisition. Calisle (2003) defined morphological awareness is the ability to reflect on and manipulate morphological units in word structure. Additionally, Freitas Junior, Mota, Deacon (2018) also mentioned that morpheme is the smallest unit of meaning that construct words. Then, if leaners acquire and understand that a word consists of morphemes; they will be able to identify words even though they have not seen those words. As McBride-Chang, Tong, and Wong's study (2009), morphological awareness is increasingly important as a strong predictor of vocabulary knowledge. It can be referred that learners who possess morphological awareness, they can extract and understand words even those words are unfamiliar to them.

Nagy and Anderson (1984) reported that children may learn 3,000 unknown words per year when they read texts. Moreover, children between the age of 12 months and 18 years can acquire 10 words per day if they hear new vocabularies used in their environment (Bloom, 2002). It is, therefore, the awareness of morphological structure which is significant to literacy and vocabulary developmental levels of performance (Wolter \& Pike, 2015). Thus, morphological awareness also has an impact on learner's vocabulary knowledge; learners can acquire more complex words faster and successfully when they understand the structure of words or they possess morphological awareness.

Morphological awareness is also related to language acquisition in which it leads to literacy skills as well as vocabulary knowledge. According to Osborne and Mulling's research (2001), there is the negative effect of lacking morphological awareness towards English vocabulary acquisition of Spanish-speaking ESL learners. The researchers found that in those students have limited knowledge of English inflectional and derivational morphology. Furthermore, Choi (2015) studied about the role of L1 (Korean) and L2 (English) derivational morphological awareness in L2 (English) reading through the mediation of L2 (English) vocabulary knowledge and found that L2 (English) deviational morphological awareness directly affects to L2 (English) reading comprehension in which ESL are struggling to learn to read new words. It is because if inflectional and derivational morphology processing is problematic, it affects the process of L2 vocabulary acquisition. Furthermore, Masrai (2016) found that there are some significant relationships between knowledge of regular inflection and derivation and L2 vocabulary knowledge of Arabic EFL learners in which native Arabic EFL learners have difficulty extracting the irregular base words. 
According to Thailand education system, English is one of subjects in basic education core curriculum B.E. 2551 (A.D. 2008) (Ministry of Education, 2009). Thus, students are required to study English as a foreign language from preschool until university level. Those students have to acquire English language skills: listening, speaking, reading, and writing. However, the EF English Proficiency Index from 2011-2017 reported that Thailand has been ranked at a low level of English proficiency among countries in Asia. In 2017, Thailand was ranked 15 from 20 countries in Asia. Furthermore, several research revealed that Thais are struggling in using and communicating in English because they have not reached appropriate levels of English proficiency for international communication needs (Chaunchaisit \& Prapphal, 2009; Jarupan, 2013; Verhoeven \& Perfetti, 2003; Wiriyachitra, 2001).

In order to have good or excellent proficiency in English language skills, vocabulary knowledge is a major role in the formation of complete spoken and written texts (Nation, 2001). As mentioned earlier, morphological awareness is important for vocabulary knowledge in which this awareness links to being literate (Zhang \& Koda, 2013); therefore, it is better to take a long, hard look at morphological awareness so that learners can understand and acquire new words to use them to learn reading and writing successfully.

To clarify the relationship of morphological awareness and English vocabulary knowledge of EFL learners and to explore whether gender relates to morphological awareness, the present study addresses two questions: (1) Does morphological awareness relate to vocabulary knowledge of Thai EFL university students? and (2) Is there any difference of morphological awareness between male and female EFL students?

\section{LITERATURE REVIEW}

\section{A. Morphological Awareness}

Morphological awareness has been variously defined. For example, Carlisle (2003) mentioned that morphological awareness as the ability to think about and identify word structure. Similarly, morphological awareness also refers to learner's ability to analyze the smallest unit (morpheme) of word structure (Berninger, Abbott, Nagy, \& Carlisle, 2010). McCutchen and Stull (2015) explained that morphological awareness is a metalinguistic insight that word can be isolated into small meaningful units. Additionally, Koda, Sun, and Zhang (2014) added that this awareness is a multidimensional competence that leads to different aspects and level of insights. It means that morphological awareness is the ability to identify, analyze, and break words into morphological units or morphemes. However, it depends on individual performance to develop one's self to have more complex level of the awareness.

Since morphological awareness is the ability to identify and break words into the smallest units which carry meanings, therefore, it can be said that meaningful units are formed in the process of word formation in which each unit is called as morpheme (Finegan, 2008). Morphemes can be divided into two types: free and bound. Free morpheme is a morpheme that can stand alone as a word: father, mouse, happy etc. On the other hand, bound morpheme is a morpheme that cannot stand alone which can be referred to affixes (Rispens, McBride-Chang, \& Reitsma, 2008; Finegan, 2008; Verhoeven \& Perfetti, 2003). Bound morphemes are used for word formation process: derivation and inflection. As the derivation process, the morpheme called as derivational morpheme is added to a root word to change the part of speech of the word (Finegan, 2008). For example, the word "work", which acts as the verb, can be changed into the noun "worker" by adding the derivational morpheme "er" meaning someone or something that performs the actions. Meanwhile, the morpheme added to a root word in word formation process is referred to the inflectional morpheme which creates variant form of word to conform to different roles in a sentence such as tense, number, and degree (Finegan, 2008). For instance, the sentence "I walk" is present tense. The inflectional morpheme "-ed" is added to the verb "walk" (present tense) as "walked" (past tense) to change the sentence from present tense to past tense.

\section{B. Morphological Awareness and Vocabulary Knowledge}

Vocabulary knowledge is a critical component to learn language (Hayashi \& Murphy, 2011). Several studies have been documented that there is a linkage between morphological awareness and vocabulary knowledge. McBride-Chang, Wagner, Muse, Chow, and Shu (2005) did research on the role of morphological awareness in children's vocabulary acquisition in English and found that morphological structure awareness and morpheme identification together predicted an additional unique $10 \%$ of variance in vocabulary knowledge, for a total of $58 \%$ of the variance explained; that is, both morphological structure awareness and morpheme identification tests were uniquely associated with vocabulary knowledge.

In addition, Wolter and Pike (2015) also confirmed that there is a relationship between morphological awareness and vocabulary knowledge. The participants in their study asked to define 16 derived morphologically complex words and the result of the test revealed that those participants could reflect on known morphological units and many of them successfully inferred the meaning of unknown words. Similarly, McCutchen and Stull (2015) insisted that morphological awareness assists word production for students in their study. In other words, when learners are aware of word structure; they can acquire new and unknown words and also know how to make words and segment words into morphemes

\section{Morphological Awareness and Vocabulary Knowledge in EFL Contexts}


As morphological awareness is an important factor for vocabulary knowledge. There are many researchers who studied morphological awareness and vocabulary knowledge of leaners of English as a second of foreign language (ESL/EFL) (Nurhemida, 2007; Lam, Chen, Geva, Luo, Li, 2012; Hayashi \& Murphy, 2011). Nurhemida (2007) studied the relationship between morphological awareness and English vocabulary knowledge of Indonesian senior high school students and found that there was a significant relationship between the students' performance in the vocabulary level test and the morphological awareness tasks. Additionally, Lam, Chen, Geva, Luo, and Li (2012) researched on roles of L1 and L2 derivational morphological awareness in L2 reading through the mediation of L2 vocabulary knowledge of Korean EFL students. The results revealed that L2 vocabulary knowledge had a significant relationship with L2 derivational morphological awareness and reading comprehension. According to Hayashi and Murphy's study on morphological awareness in Japanese learners of English, it showed that L2 vocabulary knowledge can be explained by higher degrees of metalinguistic awareness that includes explicit knowledge of morphological segments (Hayashi \& Murphy, 2011).

\section{METHODS}

\section{A. Participants}

The participants of this study were Thai EFL university freshmen in lower northern region of Thailand who are taking bachelor's degree majoring in English. Systemic sampling was used to choose 100 university freshmen from four universities in the region.

\section{B. Design}

The researcher used the quantitative method to collect data. In this case, the researcher followed a methodology suggested by Creswell (2003) in which data was collected and explained the probable relationship between independent and dependent variables. In this case, the independent variable was gender; meanwhile, the dependent variables were morphological awareness and vocabulary knowledge. Then, the researcher tested the relationship of morphological awareness and vocabulary knowledge.

\section{Instrument}

The morpheme identification test was applied as research instrument to collect quantitative data. The test was adapted from Nelson-Denney Reading Test which is a reading survey test for high school students, college students, and adults that measures vocabulary development, comprehension, and reading rate. Additionally, the list of vocabularies in the morpheme identification test was derived from Cambridge Vocabulary for IELTS by Cullen (2008).

\section{Procedure}

The participants were given the test which contained 50 complex words. The test was divided into 2 parts: selfchecking and morpheme breakdown. To do the test, the participants were asked to check the 50 words whether they knew them or not. They had to check by using a tick if they knew the words $(\sqrt{ })$. If not, using a cross (x) was for unknown words. After self-checking, the participants were also requested to complete the test by identifying the words in the previous part and breaking them into morphological units within an hour. The scores were given if the participants could correctly break a word into morpheme

\section{E. Data Source and Analysis}

The quantitative data analysis was conducted with data obtained from the morpheme identification test. Descriptive statistic was employed to summarize the scores from the test. In addition, Pearson Correlation Coefficient was also used to find out the relationship between morphological awareness and vocabulary knowledge of Thai EFL university freshmen.

\section{RESULTS AND DISCUSSION}

In this study, the researcher investigated the relationship between morphological awareness and vocabulary knowledge of Thai EFL university students in the lower northern region of Thailand. Additionally, the present study elicited information on gender and morphological awareness. The results gained from 100 participants were analyzed as follows:

TABLE I.

THE Numbers AND PERCENTAGE OF PARTICIPANTS (N=100)

\begin{tabular}{|c|c|}
\hline Gender & Total (\%) \\
\hline Male & $24(24.0 \%)$ \\
\hline Female & $76(76.0 \%)$ \\
\hline
\end{tabular}

According to Table I, it revealed the numbers and percentage of participants joined in this study in which there were 24 male students $(24.0 \%)$ and 76 female students $(76.0 \%)$. 
TABLE II.

OVERALL SCORE, MEAN SCORE, AND STANDARD DERIVATION (N=100)

\begin{tabular}{|c|c|}
\hline & Score $(50)$ \\
\hline Lowest & 7.0 \\
\hline Highest & 41.0 \\
\hline Mean score (Mean \pm Standard Derivation $S D)$ & $28.42 \pm 6.45$ \\
\hline
\end{tabular}

Furthermore, Table II showed the mean score of the test which was 28.42 out of 50 points with the standard derivation (SD) 6.45. As shown in Table II, it was also found that the highest score was 41 points and the lowest score was 7 points.

To clarify more about the scores gained from the test, it can be separated into ranges as shown in Table II

TABLE III.

THE RANGE OF SCORES FROM THE TEST (N=100)

\begin{tabular}{|c|c|}
\hline Range & Number (Percentage \%) \\
\hline $0-10$ & $1(1.0)$ \\
\hline $11-20$ & $10(10.0)$ \\
\hline $21-30$ & $55(55.0)$ \\
\hline $31-40$ & $33(33.0)$ \\
\hline $41-50$ & $1(1.0 \%)$ \\
\hline
\end{tabular}

According to Table III, it was found that $55 \%$ of the participants was in the score range of 21 to 30 ; meanwhile, $33 \%$ of them had a score with a range between 31 and 40 . The $10 \%$ of the participants had scores from 11 to 20 and $1 \%$ was at $0-11$ points and 41-50 points, respectively.

As seen in Table IV, gains in vocabulary were apparently associated with morphological awareness which referred that there was the positive and linear relationship between vocabulary knowledge and morphological awareness. That is,

TABLE IV.

THE RELATIONSHIP BETWEEN MORPHOLOGICAL AWARENESS AND VOCABULARY KNOWLEDGE

\begin{tabular}{|c|c|c|c|c|c|}
\hline Score Item & $\mathrm{N}$ & $\overline{\mathrm{x}}$ & SD & Pearson Correlation & Sig \\
\hline Vocabulary Knowledge & 100 & 33.69 & 7.57 & \multirow{2}{*}{$0.560 *$} \\
\hline Morphological Awareness & 100 & 28.50 & 6.53 & 0.000 \\
\hline
\end{tabular}

the mean score of vocabulary knowledge and morphological awareness was 33.69 with SD 7.57 and 28.50 with SD 6.53 respectively. The reliability of the relationship of morphological awareness and vocabulary knowledge was at $\mathrm{p}<0.01$ $(99 \%)$.

In addition, the researcher investigated whether there was any difference between male and female in perceiving morphological awareness which could be linked to vocabulary knowledge. The results showed that there was not any significant difference between male and female participants as illustrated in Table V. The scores obtained from the participants (24 male and 76 female) revealed that the mean score of male was 30.58 points with SD 4.50; meanwhile,

TABLE V.

THE MORPHOLOGICAL AWARENESS SCORES OF MALE AND FEMALE PARTICIPANTS

\begin{tabular}{|c|c|c|c|c|c|}
\hline Gender & $\mathrm{N}$ & $\overline{\mathrm{x}}$ & SD & $\mathrm{t}$ & Sig \\
\hline Male & 24 & 30.58 & 4.50 & \multirow{2}{*}{$1.910^{*}$} & \multirow{2}{*}{0.059} \\
\hline Female & 76 & 27.74 & 6.84 & & \\
\hline
\end{tabular}

the mean score of female was 27.74 with SD 6.84. Therefore, it could be implied that the morphological awareness of male and female was not significantly different.

Based on the results of the present study, it could be discussed that morphological awareness can be linked to the acquisition of vocabulary and vocabulary knowledge. In other words, the awareness of word structure or morphological awareness is the predicator of acquiring and gaining new words of learners. The results were consistent with McBrideChang, Wagner, Muse, Chow, and Shu's research (2005), morphological awareness can apparently predict the ability of perceiving vocabulary and having vocabulary knowledge. It was similar to the study of Zhang and Koda (2013) which mentioned that this awareness enables learners to understand and acquire new words to use them to learn reading and writing successfully. Moreover, the results of the present study was also related to Wolter and Pike's study (2015) in which the participants in their study could reflect on known morphological units and many of them successfully inferred the meaning of unknown words. Therefore, it could be concluded that there is a relationship between morphological awareness and vocabulary knowledge. 
Due to the present study conducted in the EFL context, the results were also consistent with several studies investigated the relationship between morphological awareness of English and vocabulary knowledge of EFL learners. For example, Nurhemida (2007) studied the relationship between morphological awareness and English vocabulary knowledge of Indonesian senior high school students and found that there was a significant relationship between the students' performance in the vocabulary level test and the morphological awareness tasks. Additionally, Lam, Chen, Geva, Luo, and Li (2012) researched on roles of L1 and L2 derivational morphological awareness in L2 reading through the mediation of L2 vocabulary knowledge of Korean EFL students. The results revealed that L2 vocabulary knowledge had a significant relationship with L2 derivational morphological awareness and reading comprehension. According to Hayashi and Murphy's study (2011) on morphological awareness in Japanese learners of English, it showed that L2 vocabulary knowledge can be explained by higher degrees of metalinguistic awareness that includes explicit knowledge of morphological segments. The results of the present study also revealed that there was the positive relationship between morphological awareness and vocabulary knowledge. In other words, the participants could segment known and unknown words into small units correctly. It was because the morphological awareness enables them to understand each unit of word.

\section{CONCLUSION AND RECOMMENDATIONS}

The conclusion of the study is that Thai EFL university students had a sufficient level of morphological awareness which enabled them to have vocabulary knowledge of English. In other words, the majority of participants could separate words into morphemes correctly even though they have not seen those words. In this study, gender is the factor investigated whether it affected the ability of acquiring morphological awareness and vocabulary knowledge of English. According to the results of the present study, it was found that there was no significant difference of morphological awareness and vocabulary knowledge of English between male and female students. This can be implied that male and female students have the equal level of acquiring morphological awareness and gaining vocabularies. Therefore, it can be concluded that there is a relationship between morphological awareness and vocabulary knowledge in which this awareness assists learners to understand how they can break words into morphemes correctly even if it is a new or an unknown word for them.

The study also led to three suggestions. First, future studies should look in greater depth into morphological awareness and language skills. Second, investigations should explore whether EFL students in lower grades possess an adequate level of morphological awareness since this awareness is the predicator of being literate. Finally, more research should explore methods or techniques which could.

\section{ACKNOWLEDGMENTS}

The authors wish to thank all participants who joined this study without whose co-operation; it could not have been carried out. In addition, this work was supported in part by a grant from Naresuan University.

\section{REFERENCES}

[1] Berninger, V. W., Abbott, R. D., Nagy, W., \& Carlisle, J. (2010). Growth in phonological, orthographic, and morphological awareness in grades 1 to 6. Journal of Psycholinguistic Research, 39, 141-163.

[2] Bloom, P. (2002). How Children Learn the Meaning of Words. Cambridge: MIT Press.

[3] Carlisle, J. F. (2003). Morphology matters in learning to read: A commentary. Reading Psychology, 24, 291-332.

[4] Chaunchaisit, S. \& Prapphal, K. (2009). A study of English communication strategies of Thai university students. MANUSYA: Journal of Humanities, 17, 100-126.

[5] Choi, T-H. (2015). The impact of the teaching English through English' policy on teachers and teaching in South Korea, Current Issues in Language Planning, 16.3, 201-220.

[6] Creswell, J.W. (2003). Research design: Qualitative, quantitative, and mixed method approaches. Thousand Oaks: Sage Publications.

[7] Cullen, P. (2008). Cambridge vocabulary for IELTS. Cambridge: Cambridge University Press.

[8] Finegan, E. (2008). Language: Its Structures and Use. Boston: Wadsworth.

[9] Freitas Junior, P. V., Mota, M. M. P. E., \& Deacon, S. H. (2018). Morphological awareness, word reading and reading comprehension in Portuguese. Applied Psycholinguistics, 39.3, 507-525.

[10] Hayashi, Y., \& Murphy, V. (2011). An investigation of morphological awareness in Japanese learners of English. Language Learning Journal, 39.1, 105-120.

[11] Jarupan, S. (2013). The English oral communication competency of Thai engineering students. International Journal of Scientific and Research Publications, 2.3, 1-9.

[12] Koda, K., Sun, X., \& Zhang, D. (2014). Morphological awareness in biliteracy acquisition: A study of young Chinese EFL readers. International Journal of Bilingualism. 18.6, 570-585.

[13] Lam, K., Chen, X., Geva, E., Luo, Y. L., \& Li, H. (2012). The role of morphological awareness in reading achievement among young Chinese-speaking English language learners: A longitudinal study. Reading and Writing, 25, 1847-1872.

[14] Masrai, A. (2016). The influence of morphological knowledge on lexical processing and acquisition: The case of Arab EFL learners. Ampersand, 3, 52-60. 
[15] McBride-Chang, C., Wagner, R. K., Muse, A., Chow, B. W. -Y., \& Shu, H. (2005). The role of morphological awareness in children's vocabulary acquisition in English. Applied Psycholinguistics, 26.3, 415-435.

[16] McBride-Chang, C., Tong, X., Wong, A. M-Y. (2009) Morphological awareness, orthographic knowledge, and spelling errors: Keys to understanding early Chinese literacy acquisition. Scientific Studies of Reading, 13.5, 426-452.

[17] McCutchen, D., \& Stull, S. (2015). Morphological awareness and children's writing: Accuracy, error, and invention. Reading and Writing, 28.2, 271-289.

[18] Ministry of Education. (2008). The Basic Education Core Curriculum B.E. 2551 (A.D. 2008). http://www.act.ac.th/document/1741.pdf (accessed 11/10/2017).

[19] Nagy, W. E., \& Anderson, R. C. (1984). How many words are there in printed school English?. Reading Research Quarterly, 19.3, 304-330.

[20] Nation, I. S. P. (2001).Learning vocabulary in another language. Cambridge: Cambridge University Press

[21] National Council of Teachers of English. (2013). 21st Century Literacies, Curriculum, Instruction, Literacy, Reading. http://www2.ncte.org/statement/21stcentdefinition/ (accessed 23/5/2017).

[22] Nurhemida. (2007). The relationship between morphological awareness and English vocabulary knowledge of Indonesian senior high school students. University of Queensland, St Lucia, Australia. https://www.asian-efl-journal.com/Thesis/ThesisNurhemida.pdf (accessed 30/9/2016).

[23] Rispens, J. E., McBride-Chang, C., \& Reitsma, P. (2008). Morphological awareness and early and advanced word recognition and spelling in Dutch. Reading and Writing, 21.6, 587-607.

[24] Tomkins, G. (2013). Literacy for the 21st Century: A Balanced Approach. New York: Pearson

[25] Thoughtful Learning (no date). https://k12.thoughtfullearning.com/FAQ/what-are-21st-century-skills (accessed 5/9/2017).

[26] Osborne, A., \& Mulling, S. (2001). Use of morphological awareness by Spanish L1 ESOL learners. International Review of Applied Linguistics, 39, 153-159.

[27] Verapornvanichkul, P. (2011). A survey of problems in oral communication skills when dealing with English speaking clients: A case study of employees at one of the big 4 audit firms in Thailand Thammasat University, Thailand. http://digi.library.tu.ac.th/thesis/lg/0620/title-appendix.pdf (accessed 11/1/2018).

[28] Verhoeven, L., \& Perfetti, C. A. (2003). The role of morphology in learning to read. Scientific Studies of Reading, 7, $209-217$.

[29] Wiriyachitra, A. (2001). A Thai university English scenario in the coming decade. Thai TESOL, 14.1, 4-7.

[30] Wolter, J.A., \& Pike, K. (2015). Dynamic assessment of morphological awareness and third-grade literacy success. Language, Speech, and Hearing Services in Schools, 46, 112-126.

[31] Zhang, D., \& Koda, K. (2013). Morphological awareness and reading comprehension in a foreign language: A study of young Chinese EFL learners. System, 41, 901-913.

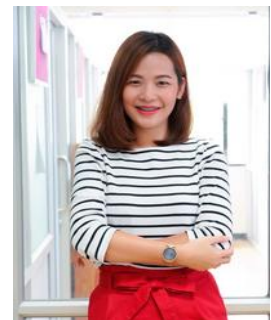

Sarunya Tarat was born Uttaradit, Thailand in 1985. She did her BA in linguistics from Thammasat University in Bangkok, Thailand in 2008 and MA in English from Srinakharinwirot University in Bangkok, Thailand in 2013.

She is a lecturer of English for Business Communication Program (International Program) at Naresuan University International College, Naresuan University, Phitsanulok, Thailand. She has taught a number of courses on English language skills over the years, as well as linguistic courses such as phonetics, phonology, morphology, and syntax. Her research and publication interests include applied linguistics, language acquisition, and communication. 